\title{
LATE RESULTS IN EPIDEMIC ENCEPHALITIS *
}

\section{MORRIS GROSSMAN, M.D.}

Adjunct Visiting Neurologist to the Mount Sinai Hospital; Adjunct Visiting Neurologist to the Montefiore Home and Hospital for Chronic Diseases

NEW YORK

There were about 145 cases of epidemic encephalitis in the neurological and medical services at the Mount Sinai Hospital during the epidemics of this disease in 1919 and 1920. A great many of these patients left the hospital soon after the acute infection had subsided, showing some residual symptoms and signs of the disease. After a number of months had elapsed, we felt that it would be of interest to reexamine these patients in order to determine what, if any, changes were still present. With this object in view, this follow-up study was undertaken. Altogether eighty-nine patients were reexamined, and these examinations comprise the basis for this report.

In order to be reasonably certain that none of the symptoms or residual signs found at this reexamination were still part of the acute stage of the disease, at least six months were allowed to elapse before a patient was reexamined. The earliest cases were seen late in 1918, so that some of the patients were examined approximately two years after their acute illness. A complete neurologic examination was made in each case. No attempt will be made in this communication to correlate the symptoms and physical findings in the reexamination with those noted during the acute stage of the illness.

The findings in the cases may be grouped under these headings: (1) psychic disturbances, (2) tremor and irregular involuntary movements, (3) disturbances in attitude and gait, (4) disturbances in tonus and reflexes, (5) residual symptoms in cranial nerves, (6) pupillary disturbances, (7) epilepsy, (8) other residual symptoms and signs, (9) progressive cases, and (10) mortality in these 145 cases.

\section{PSYCHIC DISTURBANCES}

Fifty-one of the eighty-nine patients studied showed derangement in their psychic functions in one form or another; twenty-six of these complained of various degrees of irritability; six patients had become so irritable since their illness that they quarreled with everybody who came in contact with them. A number stated that they had no desire

\footnotetext{
* From the Neurological Service of the Mount Sinai Hospital, New York City.

* Read at the first annual meeting of the Association for Research in Nervous and Mental Diseases, Dec. 29, 1920.
} 
to associate with any one, and preferred to be alone. They complained of restlessness, were easily disturbed, and would be startled and frightened at the slightest noise. They were unable to concentrate on any subject, and lacked interest in current events. Their mental reactions were retarded, and they were slow in following topics which were being discussed. Slight efforts produced undue physical and mental fatigue. These symptoms were particularly striking in those patients who showed symptoms pointing to involvement of the pituitary or basal ganglions.

Emotional instability was present in many of these patients, and in the majority it was evidenced in a marked depression. They were easily moved to tears, and worried continually-some because they could not sleep, and others because their various symptoms persisted so long after their acute illness was over. A number were worried because they still suffered from drowsiness. A few felt happy and unconcerned; they displayed a feeling of well being that was not in accord with what their physical examination disclosed. Two of these patients were euphoric, and presented a psychomotor activity which was a!most equal to that seen in hypomanic states.

There were a number of well-defined cases of fear and compulsion neuroses. One patient, a girl aged 23, was in constant fear that she would commit suicide. She would always have to repress an impulse to jump out of a window, or throw herself before a train. Another patient, a man of 39 , was in constant fear of being arrested, even though he felt positive he had done no wrong. A third man was afraid to stay home alone; he did not know what he feared, but felt safe if any one, even a child, would stay in the house with him. He realized how absurd his fear was, but maintained that he could not help or understand it. Another patient, a woman aged 33, could not fall asleep because she could not keep her thoughts away from people she knew who had died. Still another patient could not sleep because many details of the work he had done that day would repeatedly be reviewed.

Disturbance in memory, especially for recent events, was a common complaint. One patient, a student in accountancy, found that since his illness, in addition to defects in memory for recent events, he was having increasing difficulty in handling figures.

Changes in disposition were marked in three children. One, a boy of 10, had a mild attack of encephalitis in March, 1920. Previous to his illness his mother stated that she had great difficulty in managing this child because he was wilful, quarrelsome, and always up to some mischief; since his illness, he has become docile, obedient, and amiable, and never quarrels with his brothers and sisters as he had always done before his illness. Physical examination showed twitching in the 
muscles supplied by the upper and lower branches of the right facial nerve and some residue in the other cranial nerves. He had gained twenty pounds; his mental reactions were slow and he resembled a mild type of Fröhlich's syndrome. Another boy of 13 was said, previous to his illness in April, 1920, to be an obedient, well mannered and well behaved child; he never had any difficulty in getting along with his companions. His attack of encephilitis was mild; however, his mother states that since his illness he has become extremely irritable and quarrelsome; he is wilful and difficult to manage. He has great difficulty in his studies and has fallen behind in his school work. He has acquired a spitting tic; every few seconds he has an irresistible desire to spit, and does so accompanying the act with an explosive grunt. He states that he cannot control this desire for more than a few minutes at a time. The third child began to steal little things, and to lie about everything he did; previous to his illness he had been a well behaved child. He has become mentally slow and has difficulty with his school work.

Insomnia was a complaint in forty-nine of the eighty-nine cases; this percentage is so striking that this symptom must be considered an undoubted sequel of encephalitis. Almost all of these patients stated that it required from one to two hours before they could fall asleep, and that until the early morning hours their sleep was easily disturbed; after the early morning hours and during the daytime their sleep was more profound. Some of the reasons given for this difficulty were pains in those patients who had suffered from the radicular type of encephalitis; others, the majority, thought it was due to the fact that they could not relax completely, and that their minds were constantly active. A similar insomnia was noted in many of these patients during the acute stage of their illness. This symptom, therefore, should not be considered a purely psychoneurotic manifestation. Many of the patients complained of excessive drowsiness throughout the day; some of them even fell asleep during their working hours, and were unable to hold their positions on this account. When they went to bed at night, however, sleep was difficult and in some cases even impossible.

Based on the publicity given the disease among the laity, many patients felt that they had acquired a certain importance in having passed through the dangers from it; these patients felt heroic, yet they strongly craved for sympathy and reassurance.

A more extensive analysis of the many variations in the disturbed psychic functions encountered among these patients has not been attempted. I think, however, that sufficient detail has been given to indicate that psychoneuroses and other forms of deranged psychic functions may follow this acute inflammation of the brain. Frank psychoses were not included in this study. 
TREMOR AND IRREGULAR INVOLUNTARY MOVEMENTS

Fifty-two patients showed either tremor or some form of irregular involuntary movements. They were present in ten out of twenty-one cases eighteen months after the acute stage of the illness had passed; in eleven of twenty-one cases twelve months after; in twenty-nine of forty-two cases nine months after, and in two of five cases six months after the acute illness. Among these fifty-two patients, there were twenty-five who showed a fine or coarse tremor of either the lips, tongue, facial muscles, head, upper or lower extremities. These tremors closely resembled those seen in toxic states. The finer were like those of hyperthyroidism, and the coarser simulated those seen in chronic alcoholism. Most of the tremors were, as a rule, not evident when the parts were at rest, but became apparent when the parts were put into action. Ten of the fifty-two patients showed a tremor that was spontaneous, present while the parts were at rest, and as a rule limited to the distal parts of the extremity affected. Emotional stress caused exaggeration of the tremor, and it was said to be absent during sleep. This tremor was like the tremor of paralysis agitans. In three cases it was present in both hands; in three others it was present only in one hand; three patients presented tremor in the arm and leg of one side, and in one it was present in both arms and legs.

Tremors of the intentional type were noted in five patients. In three of these patients the tremor was present in both arms; in one the head and both arms were the seat of the tremor, and in the other all of the extremities were involved. These tremors were evident only when the parts affected were in action. They were characterized by large, coarse, irregular oscillations, with a variable range of movement which tended to increase as the goal was reached. They closely resembled the tremors seen in multiple sclerosis and cerebellar disease. One of the patients, in addition to the tremor, had nystagmus, scanning speech, and walked with an ataxic gait. She was, however, improving progressively.

Five patients had a rapid clonic twitch of the muscles supplied by one or more branches of the facial nerve. This twitching closely resembled the muscular response obtained when the nerve is stimulated with an electric current. It occurred every few seconds, was rapid, and always definitely anatomically limited to the muscles supplied by the particular branch involved.

Three of the patients had choreiform movements of the tongue, face or extremities. Three others had fibrillary tremor of the tongue; two of these were associated with a unilateral atrophy of the tongue. One patient had myoclonic movements of the perineal muscles one year after the acute illness. 
DISTURBANCE IN ATTITUDE AND GAIT

Fourteen of the eighty-nine patients had disturbance in their atticude or gait, four patients-children-had the typical attitude and gait of paralysis agitans. The youngest was $7 \frac{1}{2}$ and the oldest 16 years. Five other patients showed similar attitudes and in addition walked with a hemiplegic gait. Loss of associated movements was present in five of these nine patients. Propulsion was present in four, and in one of these retropulsion was also obtained. Three patients walked with a spastic paraplegic gait and two walked with a right hemiplegic gait.

\section{DISTURBANCE IN TONUS AND REFLEXES}

Muscle tone was disturbed in seventeen cases. In four of these there was slight increase; in five there was moderate increase, but not sufficient to produce the "cog-wheeel" phenomenon; in five others there was a marked increase, and the "cog-wheel" phenomenon was elicited. In two patients tonus was diminished in the muscles of the lower extremities, and one patient showed well-marked dystonia in the muscles of both thighs.

The deep reflexes were altered in twenty-seven cases; in eleven of these patients, the deep reflexes were greatly increased, but equally so on both sides. In fifteen the deep reflexes were unequal, being more active on one side than on the other. In one case, the right ankle reflex was absent, and the left was greatly diminished, while both knee reflexes were exaggerated.

The Babinski phenomenon was definitely present in six cases, and doubtful in one. In two of the six patients it was present on both sides, while in the four others it was present only on one side. Three of these patients presented clinically paralysis agitans features. In one of the patients there was associated with a bilateral Babinski sign, hypotonus at the ankles and loss of the right ankle jerk.

\section{CRANIAL NERVE AND PUPILlaRY DISTURBANCES}

Some disturbance in the cranial nerves was present in fifty-seven of the eighty-nine patients. In thirty-six of these slight facial inequality was noted on one side; two others showed bilateral facial weakness. The slight disturbance in facial enervation in the majority of the cases seemed to be supranuclear in origin. Nine of the patients had both facial and external rectus involvement; two implication of the external rectus alone. Two had atrophy of the tongue and one had fibrillary tremor without atrophy. One patient had deviation of the tongue to the right, and one had paralysis of the soft palate on the right side. Five had some disturbance in the optic nerves during the acute stage of their illness. In this reexamination in only one patient definite changes in 
the optic nerves were found; this girl had a temporal pallor on the right side and almost complete atrophy of the left nerve head. No optic neuritis was noted during the acute stage of this patient's illness. She also complained of diminution of hearing on the left side, but there were no objective signs of disturbed function present.

Incomplete ptosis of one eyelid was present in sixteen cases; on both sides in seven others. The pupils were unequal in twenty-six cases. Irregularity of the outline of the pupils was notetd in five. Disturbance in the reflex to light or convergence was present in twenty-six cases; in ten of these there was a sluggish and incomplete reaction to light in both pupils; in seven others only one pupil was affected. In four patients there was a sluggish reaction to light on one side and complete loss of reaction on the other, with sluggish reactions to convergence in one or both pupils. Argyll Robertson pupils were present in five cases; in three of these it was present on one side only, and in two on both sides. One patient who had atrophy of the optic nerves, had what appeared to be on rough testing, a left homonymous hemianopsia, and the pupils were sluggish.

\section{EPILEPSY}

Three patients suffered from grand mal or petit mal attacks since their acute illness. The patient with the grand mal attacks had, since his acute illness in January, 1920, four seizures in which there was complete loss of consciousness for a period of from five to ten minutes. He also had a great many seizures in which he did not lose consciousness. The other two patients, both men, one 27 and the other 48 years of age, have been suffering since their acute illness from attacks of spasmodic contraction of the right side of the face. These attacks come on at frequent intervals, last from thirty to sixty seconds, and in the older of the patients are accompanied by vertigo, confusion and difficulty in speech which lasts from one to two minutes. If the men are standing when the seizure occurs they must grasp some near-by object to keep from falling. Any number of attacks occur each day.

\section{OTHER RESIDUAL SIGNS AND SYMPTOMS}

Headache and generalized pains in the various parts of the body was a most common complaint. The headaches presented no special characteristics; they were located over any part of the cranium, and were as a rule diffuse. Burning on the top of the head and behind the eyes was frequently an annoying sequel. Pains in the body and extremities was a frequent complaint of those patients who had suffered from the radicular form of encephalitis. Some of these patients stated that their pains were as severe as during the acute stage of their illness; 
most of them, however, felt that their pains were gradually getting less severe.

Exophthalmos was noted in four cases. It was present on both sides, and was unaccompanied by any other signs of hyperthyroidism, with the exception of tremor of the hands. Tremor of the hands, however, was present in so many of the patients that it could not definitely be attributed to hyperthyroid activity in these patients.

Increase in weight sufficient to be noted by the patient or his people was found in fifteen cases. In thirteen of these the amount gained above the best previous weight was $15,15,17,20,20,25,25,35,38,45,48,50$ and 95 pounds. In two the exact amount gained was not definitely known. Many of these patients showed some other manifestations of disturbed pituitary function.

\section{PROGRESSIVE CASES}

Seven of the patients gave definite evidence of progression in their disease at the time they were examined. Five of these were of the paralysis agitans type. They showed the typical attitude, gait, tremor, rigidity, and reslessness seen in this disease. In some of these, disturbance in associated movements was also present. One of the other two patients, a man 30 years old, has gained ninety-five pounds in weight since his illness sixteen months ago; he is mentally sluggish and always drowsy; six months ago fibrillary tremor and atrophy of the left half of his tongue were noted. He is progressively getting worse. The other patient was taken ill in November, 1919. At the time her physical examination revealed bilateral facial weakness, tremor of the tongue, intention tremor and rigidity with cog-wheel phenomenon in both arms; her attitude and gait were that of a patient with paralysis agitans. In December, 1920, reexamination showed that she walked with a peculiar gait, not unlike that seen in progressive torsion spasm; there were choreiform and choreo-athetoid movements of the face, neck, shoulders and lower extremities. There was a constant uncontrollable grinding of her teeth. While seated, her pelvis and lower extremities were constantly being twisted by involuntary spasms of the muscles. Her pupils were irregular and almost completely immobile in their reactions to light and convergence. There was slight flattening of the facial folds on the right side. Dystonia was present in the muscles of the lower extremities. The deep and superficial reflexes were present and equally active on both sides. The Babinski sign was not elicited.

The majority of the other patients admitted that they were gradually improving. Even though they still had many complaints, they were much better and the symptoms were far less severe than they had been at the time the patients were in the hospital. 
MORTALITY

Among the 145 patients admitted to the hospital twenty-nine died, giving a mortality rate of 20 per cent. Notice was received of the death of one other patient after she left the hospital.

\section{SUMMARY AND CONCLUSIONS}

Sufficient time has not yet elapsed since the acute illness, nor is the number of cases in this study large enough, to warrant drawing absolute conclusions as to what the ultimate prognosis will be in these patients. There are, however, a number of striking facts that might be emphasized.

1. Psychic functions in some form or another were disturbed in 55 per cent. of these patients.

2. Insomnia was present in 55 per cent. of the cases.

3. Tremor and irregular involuntary movements were found in 58 per cent. of the cases.

4. The deep reflexes were altered in 30 per cent. of the cases, and tonus in the muscles was disturbed in 18 per cent.

5. The cranial nerves showed residual signs in 64 per cent. of the cases.

6. Pupillary disturbances were found in 30 per cent of the cases. Five patients had Argyll Robertson pupils.

7. About 8 per cent. of the patients gave signs of progression at the time they were examined.

8. The mortality among the 145 patients admitted to the Mount Sinai Hospital was 20 per cent.

From these findings one might venture this tentative prognosis: Probably less than 20 per cent. of the patients who become ill with epidemic encephalitis die during the acute stage of the illness, as usually only the most severe cases reach the hospital. Of those who survive the acute stage, about 10 per cent. may develop a progressive disease of the central nervous system. The remainder will make a good functional recovery in from six to twenty-four months, with the probability of progressive approach to the normal after that period. 